\title{
CRESTAL BONE PRESERVATION WITH PLATFORM SWITCHING
}

\author{
Manjit kumar ${ }^{1}$, Megha Chopra ${ }^{2}$, Udey Singh ${ }^{3}$ \\ ${ }^{1}$ Professor and Head, Department of Prosthodontics, Bhojia Dental College and Hospital, Himachal Pradesh, India \\ 2. PG student, Department of Prosthodontics, Bhojia Dental College and Hospital, Himachal Pradesh, India \\ 3. PG student, Department of Prosthodontics, Bhojia Dental college and Hospital, Himachal Pradesh, India
}

\begin{abstract}
ב-
ABSTRACT

New implant designs have appeared in the literature which claim that certain modifications may be helpful for maintaining crestal bone levels and consequently preserving normal soft tissue contours. Maintenance of soft tissue has been shown to depend on preservation of bone surrounding the implant. In order to achieve this goal, each step of the treatment must be managed carefully. This requires knowledge of pre-surgical treatment planning, site development, implant positioning, soft tissue management, provisionalization and prosthetic management.

Placement of a smaller diameter abutment on a large diameter implant platform (platform switching) has been proposed as an effective way to control circumferential bone loss around dental implants. The purpose of this paper is to evaluate the literature from an evidence based point of view regarding implant design modifications for preserving soft and hard tissue around implants.
\end{abstract}

Keywords: Crestal bone loss, Implant design, Platform shifting

\section{INTRODUCTION}

New implant designs have appeared in the literature which claim that certain modifications may be helpful for maintaining crestal bone levels and consequently preserving normal soft tissue contours. Placement of a smaller diameter abutment on a large diameter implant platform (platform switching) has been proposed as an effective way to control circumferential bone loss around dental implants. The purpose of this paper is to evaluate the literature from an evidence based point of view regarding implant design modifications for preserving crestal bone levels.

\section{Definition}

Corresponding Author: Manjit Kumar E-mail: manjitkiran@yahoo.co.in Received: $28^{\text {th }}$ July 2016 Accepted: $13^{\text {th }}$ November 2016 Online: $20^{\text {th }}$ January 2017
The concept of "platform switching" refers to the use of a smaller diameter abutment on a larger-diameter implant collar. This connection shifts the perimeter of the Implant-Abutment junction inwards toward the central axis (i.e. the middle) of the implant (Figure 1).

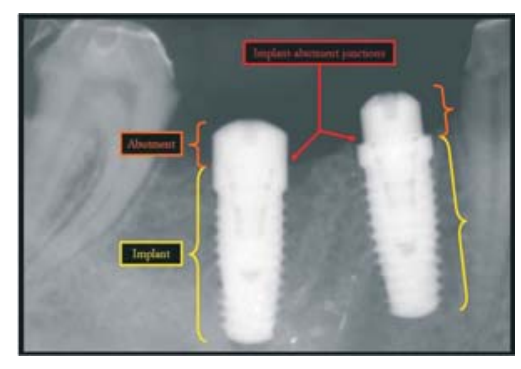

Figure 1: Intraoral radiograph showing normal implant and PLS implant

\section{Wide platform switching}

When difference of diameter of abutment and implant is larger, it is known as wide platform switching. When $4.1 \mathrm{~mm}$ abutment is used on $6 \mathrm{~mm}$ implant and difference of diameter is $1.9 \mathrm{~mm}^{2}$.

\section{Bone platform switching}

Bone platform switching involves an inward bone ring in the coronal part of the 
implant that is in continuity with the alveolar bone crest. Bone platform switching is obtained by using a dental fixture with a reverse conical neck (Figure 2). This type of implant produces increased residual crestal bone volume and carries several advantages like reduced stress and repositioning of gingival papillae. ${ }^{2}$

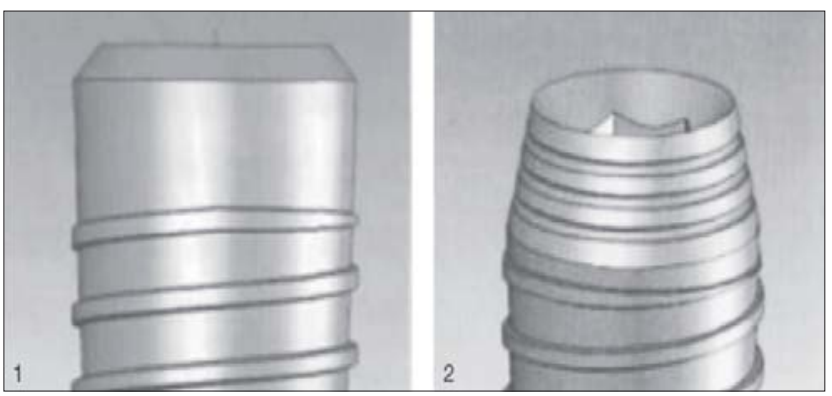

Figure 2: Normal implant and reverse conical neck implant

\section{Force dissipation on implant}

Platform switching better distributes the stress in the medial region of the implant. ${ }^{3}$ The force distribution in the platform switching restoration is slightly more favorable in a internal than in an external junction, since it improves distribution of the loads applied to the occlusal surface of the prosthesis along the long axis of the implant. The platform switching concept was able to reduce the stress and strain concentration for cortical bone compared with regular platform.

\section{Theory of platform switching (PLS)}

The concept of PLS has been considered in numerous articles, including case reports. These suggest preservation of the peri-implant bone and soft tissue conditions around PLS implants. However, there is a lack of scientific evidence regarding the biological mechanism by which it is achieved. A certain level of stable bone around the implant neck is a prerequisite for achieving support and long-lasting, optimal and stable gingival contours. In clinical settings, the incorporation of the PLS concept into the implant treatment and an understanding of the biologic width facilitates the preservation of crestal bone.
Ericsson et $\mathrm{al}^{4}$ indicated that the bone is always encircled by approximately $1 \mathrm{~mm}$ of healthy connective tissue, so it can be assumed that crestal bone remodeling takes place to create space between the bone and inflammatory cell tissue (ICT) to establish a biologic seal. PLS refers to the use of a smaller diameter abutment on a larger diameter implant collar. This type of connection shifts the perimeter of the implantabutment junction (IAJ) inward toward the central axis of the implant.

Lazzara et al, ${ }^{5}$ have hypothesized that inward movement of the IAJ is believed to shift the inflammatory cell infiltrate toward the central axis of the implant and away from the adjacent crestal bone, connective tissue thickens laterally, which increases the blood flow around that area and ICT is confined above the level of the implant platform. These changes protect crestal bone (bone around the implant shoulder) from ICT. As a result, the biologic width does not decrease in order to cover up the ICT (to establish a biologic seal) and as such, there is no bone remodeling (no crestal bone loss) (Figure 3).

(A)

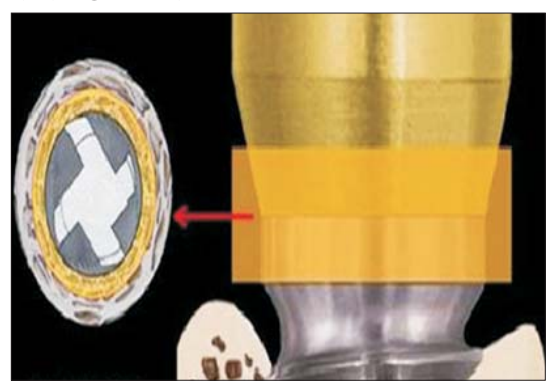

(B)

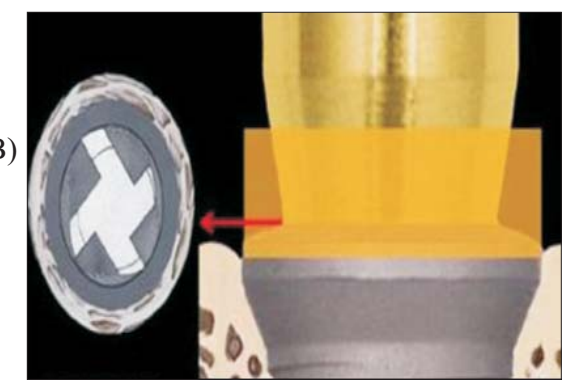

Figure 3: Inflammatory Connective Tissue (ICT) in traditional abutment design and platform switchingApical view from long axis of implant

(A) Inflammatory Connective Tissue infiltration (ICT) seen in a traditional abutment design.

(B) Inflammatory Connective Tissue (ICT) does not extend beyond the platform dimension in a platform-switched implant. 


\section{Importance of platform switching}

\section{Crestal bone loss}

Platform switching is helpful to preserve what remains and implant abutment design plays a major role. In literature it is found that immediately after the placement of implant or after any surgery on the alveolar ridge there is a loss of bone on an average of 2 $\mathrm{mm}$, it may be more if due precaution is not taken. There is horizontal as well as vertical bone loss. Preservation of crestal bone is especially important in region of sinus and alveolar canal. The bone loss cannot be afforded for better esthetics, phonetics and no food impaction in the anterior region. ${ }^{6}$

\section{Physiology of bone loss}

Early implant abutment interface incorporated a butt joint configuration initiated at two-stage surgery. These configurations resulted in bacterial contamination of the interface and an associated inflammatory infiltrate which is correlated with marginal bone loss. The magnitude of the bone loss was associated with the location of the interface relative to the bone crest. Minimum marginal bone loss occurred if the interface was located above the crest and more bone loss occurred if the interface was with the crest of the bone and greatest bone loss occur when the interface is kept apical to the crest of the bone. ${ }^{4,7}$

The size of the butt joint which ranges from 10100 micron does not affect the amount of bone loss. Comparison of studies of inflammation and bone loss around the tooth, implant and the joint suggested that inflammatory cells (B \& $\mathrm{T}$ cells) produce receptor activators of nuclear factors- Kappa B Ligand (RANKL) thus, increasing its ratio to nuclear protegrin (OPG) its natural decoy receptor. The osteoclastogenesis occurs resulting in bone loss. This is called Osteoimmunology.

\section{Factors affecting remodeling of crestal bone}

It is known that saucerization around an implant occurs following abutment connection using a submerged implant with a butt joint (a two-stage approach), such as the Branemark implant. The nature of saucerization varies according to the implant type (one-stage or two-stage) and abutment connection type. The cause of bone loss is seen in a typical buttjoint implant because this knowledge is helpful in understanding the original PLS concept. Following are the factors that most likely causes early crestal bone loss around implants: ${ }^{8}$

\section{Surgical Trauma}

Surgical trauma due to heat generated during drilling, elevation of the periosteal flap and excessive pressure at the crestal region during implant placement may contribute to implant bone loss during the healing period. Early implant bone loss is in the form of horizontal saucerization. Signs of bone loss from surgical trauma and periosteal reflection are not commonly observed at the implant stage II surgery in successfully osseointegrated implants. ${ }^{9,10}$ Thus, surgical trauma is unlikely to cause early crestal bone loss.

\section{Biological seal/Mucosal barrier}

Biologic width refers to the area of periodontal and periimplant soft-tisue structures such as the gingival sulcus, the junctional epithelium, and the supra-crestal connective tissues. Bone remodeling around an implant neck progresses until the biologic width has been stabilized.

Biological width forms within the first six weeks after the implant-abutment junction has been exposed to the oral cavity. It is a barrier against bacterial invasion and food ingress in implant-tissue interface. The ultimate location of the epithelial attachment following phase II surgery in part, determines early post-surgical bone loss. Thus, implant bone loss is in part, a process of establishing the biological seal. ${ }^{11}$

On the other hand it has been observed that the crestal bone resorption is reduced with the use of a implant with a medialized abutment as opposed to a conventional abutment. The medialized abutment horizontally shifts the implant-abutment junction (IAJ) inward, away form the crestal bone, as opposed to the conventional implant, which displays an implant and 
abutment with matching diameters. In addition, significantly more crestal bone loss was noted before functional loading than, after the prosthesis was connected in a single stage implant system.

\section{Microgap}

Numerous studies have shown that bone resorption around the implant neck does not start until the implant has been uncovered and exposed to the oral environment. Exposure invariably leads to bacterial contamination of the gap between the implant and the superstructure. $^{12}$

The bacterial contamination of the microgap between the implant and the abutment adversely affects the stability of the periimplant tissue. If above average axial forces are exerted on the implant, it may cause a pumping effect, resulting in a flow of bacteria from the microgap, thus provoking the formation of inflammatory connective tissue (ICT) in the region of the implant neck.

\section{Occlusal load}

\section{a. Overload}

Excessive stress on the immature implant bone interface in the early stage of prosthesis in function is likely to cause crestal bone loss. Cortical bone is least resistant to shear force, which is significantly increased in bending overload. However, bone loss from occlusal overload is considered to be progressive rather than limited to the first year of loading. The occlusal overload is a major cause of implant failure. ${ }^{13}$ Thus, this phenomenon could explain saucerization around the implant neck during the first year of function.

\section{b. Immediate loading}

Canullo et $\mathrm{al}^{14}$ reported on short-term bone level response around single, immediately placed and provisionalized PLS implants and the average bone resorption level in the PLS group was smaller than that in the non PLS group. Bone resorption around a PLS implant recorded was $0.78-1.36 \mathrm{~mm}$, which is significantly lower than the mean reference value of 1.7 $\mathrm{mm}$.

\section{c. Progressive loading}

Progressive loading of the implants was first suggested by Misch in 1980. The crestal bone loss after successful bone integration was related directly to the bone density. An implant may fail if the stresses applied exceed the physiologic limits of the bone density present around the implant.

Appleton et $\mathrm{l}^{15}$ determined the effectiveness of progressive loading procedures on preserving crestal bone height and improving peri-implant bone density around maxillary implants. The mean values of crestal bone height loss at 12 months were $0.2+0.27 \mathrm{~mm}$ for progressively loaded implants and $0.59+0.27 \mathrm{~mm}$ for the conventionally loaded implants. The peri-implant density measurements of the progressively loaded implants showed continuous increase in peri-implant bone density by time.

\section{d. Immediate implant placement}

Immediate implant placement has become a major contributing success factor in compromised bones. Placing immediate implants after tooth extraction will help in preserving the denser bone and preventing the atrophy and results in less loading of the marginal bone.

More than $90 \%$ success rate for immediate implants has been well documented histologically as well as radiographically. The placement of immediate implant and provisional restoration following minimally invasive extraction to preserve the anterior esthetics. The implant was placed immediately after extraction without any flap reflection. They concluded that this strategy preserves optimum gingival contours and papillary height by preserving the crestal bone than delayed implants and some studies do not find any difference.

Younis et al compared crestal bone remodeling following both immediate and delayed placement of titanium dental implants in the extraction sockets. The width and the depth of the defects located in the mesial and the distal sides of the implants were evaluated radiographically using computer software. The mean reduction of the bone defects were $48 \%$ in the case of 
immediately placed implants, but it was only $17 \%$ in the case of delayed implants. They concluded that immediate implantation offers advantages of significant reduction in crestal bone resorption. ${ }^{16}$

Block et al determined that there is a significant difference in the hard and soft tissue response, comparing immediate with delayed implant placement after tooth removal. The analysis showed no significant differences between the two groups in the crestal interdental bone movement on either the implant or the adjacent tooth. There was a significant difference in the position of the facial gingival margin, with a more apical position of the facial gingival margin in the delayed group compared with the immediate group. ${ }^{17}$

\section{Crest module}

The crest module of the implant, which is the transosteal region of the implant, receives crestal stresses during loading (Fig.4). Once the implant undergoes loading, bone resorption is observed down to the first thread in many submerged implant systems, irrespective of the distance from the implant platform

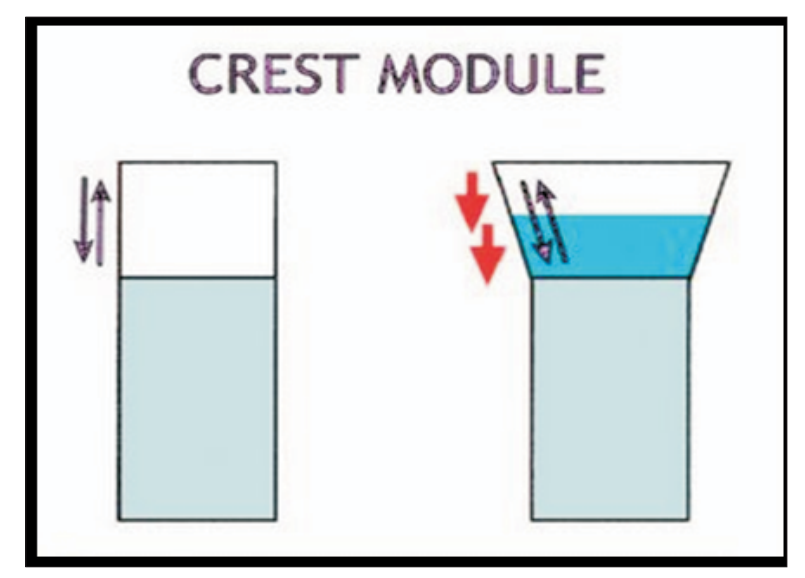

Figure 4: Crest module of a dental implant

to the first thread. Oh et $\mathrm{al}^{18}$ speculated that bone loss might relate to the crest module design rather than a specific length. They also hypothesized the bone resorption may abate at the first thread as the shear force on the crest module becomes a component of the compressive force caused by the thread itself. Functioning implants creates many forces, such as rotational, shear and compressive. The cortical bone layer is able to withstand compressive forces better than it can withstand those other forces.

\section{Crestal position of the platform}

The most coronal portion of the implant platform that is positioned at the level of the crestal bone inter-proximally as the bone loss for the platforms positioned at the crestal level varied from $0.76 \mathrm{~mm}$ and $0.77 \mathrm{~mm}$ mesial and distal, respectively, after 12 months of follow-up, recommended the use of platform switching at crestal level for preservation of the marginal bone level. When the implant-abutment interface (IAI) is located at the crestal or subcrestal level, the resorption of $2 \mathrm{~mm}$ of marginal crestal bone is observed as a result of establishment of the biological width, which acts as the mucosal barrier over the crestal bone. The amount of bone resorption required to establish the biological width decreases when the implant platform is placed at crestal level.

\section{Supracrestal position of the platform}

Several authors have suggested an association between bone loss and platform insertion depth, with inflammatory infiltration as a linking factor. So, one way to separate inflammation from the bone is to vertically displace the implant abutment interface with respect to the bone crest i.e. placing the platform at supracrestal level. If the IAI is positioned above crestal level, marginal bone loss will be smaller than when positioned below crestal level, because the supracrestal position increases the distance between the inflammatory infiltrate at the IAI and the crestal bone.

\section{Design modification and implant neck geometry}

Microthreads increased crestal stress upon loading. Platform switching resulted in less stress translated to the crestal bone in the microthread and smooth-neck groups. HA coated neck because of roughness causes more bacterial accumulation so more bone loss. ${ }^{19,20}$ Increasing the functional surface area of an implant will better distribute the stresses, resulting in 
lesser forces at the crest.

\section{a) Thread geometry}

Thread depth, thread face angle and thread pitch are some of the varying geometric patterns that determine the functional thread surface and affect the biomechanical load distribution of the implant. The influence of threads can be easily understood as the greater the number of threads present as well as greater the depth of threads, the more is the functional area available. It has been found that the shear force on a Vshaped thread face that is $30^{\circ}$ which is 10 times greater than the shear force on square thread. Therefore, square-shaped threaded implants will concentrate lesser forces at the crestal bone as well.

\section{b) Implant dimensions}

Increasing the implant length and width increases the surface area but it has been found that implant width is more important for crestal bone preservation than the implant length as stress values and concentration areas decreased for cortical bone when implant diameter is increased.

\section{c) Implant design}

The scalloped implant, a design by Noble Perfect (Noble Biocare AB, Zurich, Switzerland), enables the surgeon to place the implant in the residual bone which is characterized by the remaining interproximal osseous peaks. The implant is designed such that the interproximal peaks of the bone apposition area are in contact with the inert proximal peaks of the residual bone. It has been found that remodeling in such cases is significantly less when compared with flat prosthetic implant table.

Khatami et $\mathrm{al}^{21}$ described a case report in which a 22-year old subject was treated with the Nobel Perfect dental implant system after avulsion of two maxillary central incisors. Implants were placed in the avulsion socket and provisional restorations were made and cemented immediately. All ceramic crowns were cemented and followed for one year. At follow-up, no discernible clinical and radiographic changes in the soft tissue architecture and crestal bone profile were found.

\section{Repeated screwing/unscrewing}

Means disturbing the implant abutment junction and the mucosal barrier and biological width or attachment of soft tissue leads to progressive crestal bone loss. So we should be careful in impression making, try in, crown mounting for maintaining the health of the implant crestal bone. ${ }^{22,23}$

9. Peri-implant inflammation/ infectious process Peri implant inflammation or any type of infection around the implant also affects the bone remodeling.

\section{Methods to study crestal bone loss}

\section{Histometry}

Histomorphometry was used to evaluate both the quality and quantity of the peri-implant of the periimplant tissues. Analysis under the optical microscope indicated that the implant was surrounded by bone trabeculae, with approximately $65 \%$ bone-to-implant contact (BIC). No infraosseous pockets, Howship's lacunae or osteoclasts were found on the coronal segment of the implant. The trabeculae appeared under magnification to be surrounded by osteoblasts secreting an osteoid matrix (Figure 5). ${ }^{24}$

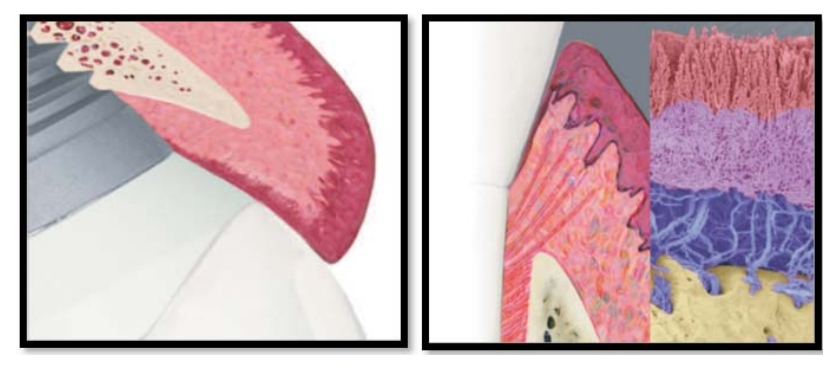

Figure 5: Histological sections.

The unstained section observed in the bright field microscopy showed a great number of osteocytes housing the bone around the implants. Under Cross Polarized Light Microscopy (CPLM) the areas with higher density of osteocytes appeared to be composed mainly of transverse collagen fibres. Generally the bone around the implant appeared to be characterized 
by mature lamellar bone, with transverse collagen fibres more represented under the lower flank of the threads.

\section{Non invasive technique}

Periapical radiograph, as a noninvasive technique $^{24}$ only allows examination of crestal bone levels precisely at mesial and distal sites of an implant if proper projection geometry is applied. With the advent of the right angle technique, the paralleling technique, and customized occlusal records combined with a long cone technique, projection errors related to rotation and angulation can be significantly decreased. Only mesial and distal crestal bone can be studied in the radiographas radiograph is a two dimensional picture (Figure 1).

\section{Finite element analysis}

Three-dimensional studies showed decreased stresses on bone in platform switching. There are three methods to study stress and strain or loading on the implants. ${ }^{25}$ These are Photoelasticity, Strain gauge placement, Finite element analysis.

These are computer studies not in wet oral conditions and does not discuss the fatigue damage of the implants. Studies compared the platform and non platform internal hex and external hex implants, platform switched with external hexed implants are more prone to fracture.

\section{Clinical benefits of PLS}

\section{Longevity increases}

As life or success of the implant prosthodontics depends on so many factors, resorption of bone around the implant is also a major factor. As there is reduction in loss of crestal bone in PLS so definitely the longevity of the prosthodontics increases.

\section{Optimum management of the prosthetic space}

The amount of restorative volume available for an optimally contoured, physiological implant restoration is a critical factor. With the crestal bone preserved both horizontally and vertically, support is thus retained for the interdental papillae. Maintenance of midfacial bone height helps to maintain facial gingival tissues.

\section{Improved bone support for short implants}

Bone remodeling around a platform switched implant is minimized, therefore, there is potentially a greater bone and implant contact for short implants, thus opening the possibility of treating more patients with less extensive therapy.

\section{Preservation of papilla and esthetics}

Since crestal bone below papilla is maintained so there will be better esthetics. Platform switching is important in case where a small amount of bone loss affects esthetics. Thick biotypes are the best candidate for platform switching.

\section{Effect of interimplant distance}

Rodriquez et $\mathrm{al}^{26}$ evaluated adjacent PLS implants placed less than $3 \mathrm{~mm}$ apart to determine whether they demonstrated less three-dimensional bone resorption than that previously reported around non-PLS implants. The PLS technique can help to preserve peri-implant bone and retain the interproximal bone peak compared to conventional (nonPLS) implant restorations.

\section{Limitations}

\section{Use larger size of implants}

If the normal size abutments are to be used, larger size implants need to be placed clinically which is not possible every time especially if the bone width is less.

\section{Emergence profile}

When we are using smaller size of abutment emergence profile is compromised especially in anterior region.

\section{Increased chances of fracture}

3D FEA study conducted by Haydal et $\mathrm{al}^{27}$ revealed that in PLS implants stresses at implant bone level decreases but on abutment and screw increases. Stresses on implant are shifted towards the centre. These are greater in cortical bone. As there are more 
stresses on the abutment there are increased chances of fracture at the site of implant abutment interface.

\section{SUMMARYAND CONCLUSION}

At present, there are only a limited number of reports on PLS, and as such, the scientific evidence is lacking in both quantity and quality. Excluding case reports, reports on PLS can be broadly categorized into; (1) prospective or retrospective radiographic evaluation of crestal bone level in humans, (2) histological and histomorphometrical analysis in animals, or (3) finite element analysis of various types and locations of implants. Most reports published so far conclude that PLS is effective in the prevention of crestal bone loss. Researchers have attempted to explain the mechanism of action of PLS; however, it is necessary to conduct further studies, including histological studies using animals, to clarify the mechanism fully. With respect to radiographic evaluations of crestal bone levels in humans, properly designed long-term observation is required, before establishing the long-term predictability of platform switching in preserving the horizontal and vertical marginal bone levels or modifying the minimum distances between platform-switched implants and adjacent teeth or implants particularly through prospective, randomized, multicenter trials with large number of participants.

\section{CONFLICT OF INTEREST-NONE IDENTIFIED REFERENCES}

1. Cocchetto R, Traini T, Caddeo F, Celletti R. Evaluation of hard tissue response around wider platform-switched implants. Int J Periodontics Restorative Dent 2010;30:163-171.

2. Carinci F, Brunelli G, Danza M. Platform Switching and Bone Platform Switching. J Oral Implant vol 35,5:245-250.

3. Ferraz CC. Influence of microthreads and platform switching on stress distribution in bone using angled abutments. J Prosthodontic Research 2012;56,4:256-263.

4. Ericsson I, Persson LG, Berglundh T, Marinello CP, Lindhe J, Klinge B. Different Types of Inflammatory Reactions in Periimplant Soft Tissues. J Clin Periodontol 1995;22:255-261.

5. Lazzara RJ, Porter SS. Platform switching: A New Concept in Implant Dentistry for Controlling Postrestorative Crestal Bone
Levels. Int J Periodont Resto Dent 2006; 26:9-17.

6. Cappiello M, Luongo R, Di lorio D, Bugea C, Cocchetto R, Celletti R. Evaluation of Per-implant bone loss around platform-switched implants. Int J Periodontics Restorative Dent 2008;28:347-355.

7. Berglundh T, Lindhe J. Dimension of the Peri-implant Mucosa. Biological width revisited. J ClinPeriodontol 1996;23:971-973.

8. Hagiwara Y. Does platform switching really prevent crestal bone loss around implants? Japanese Dental Science Review 2010; $46: 122-131$.

9. Deshpande SS, Sarin SP, Parkhedkar RD. Platform Switching of Dental Implants: Panacea for Crestal Bone Loss? J Clin Diagnostic Res. 2009;3:1348-1352.

10. Becker W, Goldstein M, Becker BE. Minimally invasive flapless implant surgery: A prospective multicenter study. Clin Implant Dent Relat Res 2005;7(Suppl.1):S21-S27.

11. Myshin HL, Weins JP. Factors affecting soft tissue around dental implants: A review of the literature. J Prosthet Dent 2005;94:440-444.

12. Weng D, Hitomi Nagata MJ, Bell M, Bosco AF, Nascimento LG, de Melo. Influence of microgap location and configuration on the periimplant bone morphology in submerged implants. An experimental study in dogs. Clin Oral Impl Res 2008;19:1141-1147.

13. Kim Y, Oh TJ, Misch CE, Wang HL. Occlusal considerations in implant therapy. Clinical guidelines with biomechanical rationale. Clin Oral Implant Res 2005;16:26-35.

14. Canullo L, Goglia G, Lurlaro G, Lannello G. Short-Term Bone Level Observations Associated with Platform Switching in Immediately Placed and Restored Single Maxillary Implants: A Preliminary Report. Int J Prosthodont 2009;22:277-282.

15. Appleton RS, Nummikoski PV, Pigno MA, Cronin RJ, Hung Chung K. A radiographic assessment of progressive loading on bone around single osseointegrated implant in posterior maxilla. Clin Oral Implant Res 2005;16:161-7.

16. Younis L, Tehar A. Evaluation of bone healing after immediate and delayed implant placement. J Contemp Dent Pract 2009; 10;35-42.

17. Block MS. Prospective Evaluation of Immediate and Delayed Provisional Single restorations. J Oral Maxillofac Surg 2009;67:89-107.

18. Oh TJ, Yoon J, Misch CE. The Causes of Early Implant Bone Loss : Myth or Science? J Periodontol 2002;73:322-333.

19. Schrotenboer J, Tsao YP. Effects of microthreads and platform 
switching on crestal bone stress levels: A finite element analysis. J Periodontol 2008;79;2166-2172.

20. Lee EH, Ryu SM, Kim JY, Cho BO, Lee YC, Park YJ, Kim SG. Effects of installation depth on survival of an hydroxyapatitecoated Bicon implant for single-tooth restoration. J Oral Maxillofac Surg 2010;68(6):1345-1352.

21. Khatami. Placement of scalloped implants after extraction of 2 maxillary central incisors: A Clinical report. J Oral Maxillofac Surg 2006;34:678-81.

22. King GN, Hermann JS, Schoolfield JD, Buser D, Cochran DL. Influence of the size of the microgap on crestal bone levels in non-submerged dental implants: A radiographic study in the canine mandible. J Periodontol 2002;73:1111-1117.

23. Abrahamssson I, Berglundh T, Lindhe J. The mucosal barrier following abutment dis/reconnection. An Experimental study in dogs. J Clin Periodontal 1997;24:568-572.

24. JoachimS.Hermann, Pirkka V. Nummikoski, Robert K. Schenk. Crestal Bone Changes Around Titanium Implants : A
Methodologic Study Comparing Linear Radiographic with Histometric Measurements. Int J Oral Maxillofac Implants $2001 ; 16: 475-485$.

25. Amilcar C. Biomechanical evaluation of internal and external hexagon platform switched implant-abutment connections: An in vitro laboratory and three-dimensional finite element analysis. Dental materials 2012;28:e 218-e228.

26. Rodriguez X, Vela Nebot X, Segala-Torres M, Calvo-Guirado J, Cambra J. The effect of interimplant distance on the height of the interimplant bone crest when using platform-switched implants. Int J Periodontics Restorative Dent 2009;29:141151.

27. Haydal. Analyzing the effect of platform switching procedure on stresses in the bone and implant abutment complex by 3 dimensional finite element study. J Oral Implant 2012;37:2125 . 